ARTICLE

DOI: $10.1038 / s 41467-018-06415-7$

\title{
An interstellar synthesis of phosphorus oxoacids
}

\author{
Andrew M. Turner ${ }^{1,2}$, Alexandre Bergantini (1) 1,2, Matthew J. Abplanalp ${ }^{1,2}$, Cheng Zhu (1) 1,2, Sándor Góbi (1) 1,2, \\ Bing-Jian Sun ${ }^{3}$, Kang-Heng Chao ${ }^{3}$, Agnes H.H. Chang ${ }^{3}$, Cornelia Meinert (1) ${ }^{4}$ \& Ralf I. Kaiser (1) ${ }^{1,2}$
}

Phosphorus signifies an essential element in molecular biology, yet given the limited solubility of phosphates on early Earth, alternative sources like meteoritic phosphides have been proposed to incorporate phosphorus into biomolecules under prebiotic terrestrial conditions. Here, we report on a previously overlooked source of prebiotic phosphorus from interstellar phosphine $\left(\mathrm{PH}_{3}\right)$ that produces key phosphorus oxoacids-phosphoric acid $\left(\mathrm{H}_{3} \mathrm{PO}_{4}\right)$, phosphonic acid $\left(\mathrm{H}_{3} \mathrm{PO}_{3}\right)$, and pyrophosphoric acid $\left(\mathrm{H}_{4} \mathrm{P}_{2} \mathrm{O}_{7}\right)$-in interstellar analog ices exposed to ionizing radiation at temperatures as low as $5 \mathrm{~K}$. Since the processed material of molecular clouds eventually enters circumstellar disks and is partially incorporated into planetesimals like proto Earth, an understanding of the facile synthesis of oxoacids is essential to untangle the origin of water-soluble prebiotic phosphorus compounds and how they might have been incorporated into organisms not only on Earth, but potentially in our universe as well.

\footnotetext{
${ }^{1}$ Department of Chemistry, University of Hawaii at Manoa, Honolulu, HI 96822, USA. ${ }^{2}$ W.M. Keck Laboratory in Astrochemistry, University of Hawaii at Manoa, Honolulu, HI 96822, USA. ${ }^{3}$ Department of Chemistry, National Dong Hwa University, Shoufeng, 974 Hualien, Taiwan. ${ }^{4}$ Université Côte d'Azur, CNRS, Institut de Chimie de Nice, Nice, France. Correspondence and requests for materials should be addressed to R.I.K. (email: ralfk@hawaii.edu)
} 
T he ubiquitous presence of the phosphorus (V) oxidation state in contemporary biomolecules found in phospholipids, ADP/ATP, and RNA/DNA represents a hitherto unresolved "phosphorus problem" as the deprived solubility of phosphate minerals such as apatite $\left(\mathrm{Ca}_{5}\left(\mathrm{PO}_{4}\right)_{3}(\mathrm{~F}, \mathrm{Cl}, \mathrm{OH})\right)$ limits bioavailable phosphorus for the first organisms on early Earth ${ }^{1,2}$. Efficient prebiotic mechanisms toward the formation of highenergy phosphates such as polyphosphates containing the repeating $\left(\mathrm{HPO}_{3}\right)_{n}$ moiety and phosphate esters have remained elusive as well ${ }^{3}$. Phosphate diesters constitute the backbone of RNA and DNA-key molecules carrying the genetic information for the reproduction of all known living organisms - as well as the hydrophilic head of phospholipids, while monoesters of pyrophosphate $\left(\mathrm{P}_{2} \mathrm{O}_{7}{ }^{4-}\right)$ and triphosphate $\left(\mathrm{P}_{3} \mathrm{O}_{10}{ }^{5-}\right)$ play a critical role in cellular energy transfer as adenosine diphosphate (ADP) and triphosphate (ATP), respectively. To overcome this "phosphorus problem", soluble molecules carrying the phosphorus (III) oxidation state have been proposed with the alkylphosphonic acids $\left(\mathrm{RP}(\mathrm{O})(\mathrm{OH})_{2} ; \mathrm{R}=\right.$ methyl, ethyl, propyl, butyl) detected in the Murchison meteorite serving as soluble compounds of extraterrestrial origin ${ }^{4}$. Prebiotic phosphorus chemistry could have been initiated by phosphorus (III) or the first organisms might have oxidized bioavailable phosphorus (III) to (V). Yet, the underlying synthetic routes to these phosphorus-bearing biomolecules along with their precursors are still in their infancy. This fundamental knowledge on the origins of the phosphorus chemistry is critical to unravel how the phosphorus biochemistry and life itself might have emerged on early Earth.

In this communication, we reveal a facile and versatile pathway toward the abiotic synthesis of phosphorus (III) and (V) oxoacids in phosphine $\left(\mathrm{PH}_{3}\right)$-doped interstellar analog ices of water $\left(\mathrm{H}_{2} \mathrm{O}\right)$ and carbon dioxide $\left(\mathrm{CO}_{2}\right)$ upon interaction with ionizing radiation in the form of energetic electrons, which simulate secondary electrons generated in the track of galactic cosmic rays penetrating interstellar ices at temperatures as low as $5 \mathrm{~K}^{5}$. Phosphine has been observed in extraterrestrial environments such as in the circumstellar envelope of the carbon star IRC $+10216^{6}$ along with other phosphoruscontaining compounds such as $\mathrm{CP}^{7}, \mathrm{CCP}^{8}, \mathrm{HCP}^{9}, \mathrm{PN}^{10-12}$, and $\mathrm{NCCP}^{13}$, and also within our Solar System in the atmospheres of Jupiter and Saturn ${ }^{14,15}$. More recently, phosphine was attributed as the source of the phosphorus signal in comet $67 \mathrm{P} /$ ChuryumovGerasimenko $^{16}$. Surface reactions involving schreibersite, an iron-nickel phosphide that along with phosphates compose the bulk of phosphorus in meteorites ${ }^{17}$, in aqueous solutions resembling conditions of early Earth have been suggested, but do not fully reproduce the synthesis of alkylphosphonic acids ${ }^{18-22}$, although the phosphorylation of adenosine has been demonstrated ${ }^{23}$. Thus, the formation of biorelevant, phosphorus-bearing molecules on interstellar grains-silicate-based nanoparticles coated with a few hundred nanometers of water $\left(\mathrm{H}_{2} \mathrm{O}\right)$, methanol $\left(\mathrm{CH}_{3} \mathrm{OH}\right)$, carbon monoxide $(\mathrm{CO})$, carbon dioxide $\left(\mathrm{CO}_{2}\right)$, methane $\left(\mathrm{CH}_{4}\right)$, formaldehyde $\left(\mathrm{H}_{2} \mathrm{CO}\right)$, and ammonia $\left(\mathrm{NH}_{3}\right)$ ices ${ }^{24}$ from which interstellar phosphine would be expected to be depleted onto from the gas phase-in molecular clouds may represent a key process leading to a facile synthesis of phosphorus compounds of potential biological significance. Considering that molecular clouds constitute the nurseries of stars and planetary systems-including our ownthe identification of phosphonic acid $\left(\mathrm{H}_{3} \mathrm{PO}_{3}\right)$, phosphoric acid $\left(\mathrm{H}_{3} \mathrm{PO}_{4}\right)$, and pyrophosphoric acid $\left(\mathrm{H}_{4} \mathrm{P}_{2} \mathrm{O}_{7}\right)$ in our ices suggests that these phosphorus oxoacids might have been at least partially incorporated into our Solar System from interstellar matter via circumstellar disks. Further, these compounds could have been delivered to early Earth by comets or meteorites such as Murchison as sources of phosphorus for biomolecules with both single phosphate groups (RNA/DNA and phospholipids) and phosphate chains (ADP/ATP). Our study defines the molecular complexity of phosphorus-bearing molecules synthesized in interstellar ices and unveils where in the universe discrete, phosphorus-containing molecular precursors relevant to the origins of life might have been synthesized and even incorporated into contemporary biomolecules.

\section{Results}

Infrared spectroscopy. In the infrared spectra of irradiated, phosphine-bearing ices, critical functional groups of phosphorus oxoacids were identified at $5 \mathrm{~K}$ and also in the residues that remained after annealing the exposed ices to $300 \mathrm{~K}$ (Supplementary Tables 1 and 2$)^{25}$. These bands include stretching modes of phosphorusoxygen single and double bonds $\left[v(\mathrm{P}-\mathrm{O})\left(800-950 \mathrm{~cm}^{-1}\right), v(\mathrm{P}=\mathrm{O})\right.$ $\left.\left(1140-1300 \mathrm{~cm}^{-1}\right)\right]$, the deformation mode of the $\mathrm{OPOH}$ functional group $\left[\delta(\mathrm{O}=\mathrm{P}-\mathrm{OH})\left(1550-1710 \mathrm{~cm}^{-1}\right)\right]$, and the $\mathrm{P}-\mathrm{OH}$ moiety $[v$ $(\mathrm{O}-\mathrm{H})\left(2170\right.$ and $\left.2700 \mathrm{~cm}^{-1}\right)$. These findings suggest that functional groups linked to oxoacids of phosphorus are the results of an exposure of the ices at temperatures as low as $5 \mathrm{~K}$. Experiments with ${ }^{18} \mathrm{O}$-labeled ice constituents $\left(\mathrm{H}_{2}{ }^{18} \mathrm{O}\right.$ and $\left.\mathrm{C}^{18} \mathrm{O}_{2}\right)$ match the isotopic shifts determined for redshifted $v(\mathrm{P}-\mathrm{O})$ and $v(\mathrm{P}=\mathrm{O})$ modes by $\sim 30 \mathrm{~cm}^{-126,27}$. Therefore, the infrared analysis reveals the existence of functional groups $[\mathrm{P}-\mathrm{O}, \mathrm{P}=\mathrm{O}$, and $\mathrm{O}=\mathrm{P}-\mathrm{OH}]$ present in phosphorus oxoacids; however, considering that fundamentals and hence the absorptions of functional of oxoacids, such as phosphonic and phosphoric acid, fall in the same range, infrared spectroscopy does not allow an identification of individual oxoacids nor their isomers. In other words, functional groups are not unique to specific phosphorus oxoacids and hence do not identify any particular molecule. Therefore, alternative analytical techniques are critical.

PI-ReTOF-MS. To probe discrete molecular species, we exploited photoionization reflectron time-of-flight mass spectrometry (PIReTOF-MS) during the annealing of the irradiated ices. This method represents a unique approach to identify gas phase molecules isomer-selectively after photoionization based on their distinct ionization energies ${ }^{28}$. Here, the subliming products were photoionized in separate experiments with 10.86 and $9.93 \mathrm{eV}$ photons to elucidate the nature of the oxoacid isomer(s) synthesized. Accounting for the adiabatic ionization energies (IE) of the oxoacids $\left(\mathrm{H}_{3} \mathrm{PO}_{\mathrm{x}} ; x=1-4\right)$ (Table 1$)$, the energy of the $10.86 \mathrm{eV}$ photon is above the IE of each oxoacid; therefore, if formed and if subliming, all oxoacids can be ionized at this photoionization energy. The use of PI-ReTOF-MS necessitated isotopically labeled $\mathrm{H}_{2}{ }^{18} \mathrm{O}$ and $\mathrm{C}^{18} \mathrm{O}_{2}$ reagents to distinguish between products formed at identical masses. Phosphinic acid and hypophosphorous acid $\left(\mathrm{H}_{3} \mathrm{PO}_{2}\right)$ along with diphosphine $\left(\mathrm{P}_{2} \mathrm{H}_{4}\right)$ have a molecular weight of $66 \mathrm{amu}$; on the other hand, ${ }^{18} \mathrm{O}$-substituted phosphinic acid and hypophosphorous acid $\left(\mathrm{H}_{3} \mathrm{P}^{18} \mathrm{O}_{2}\right)$ shifts the mass by 4 to $70 \mathrm{amu}$, thus discriminating these acids from diphosphine. At the photoionization energy of $10.86 \mathrm{eV}$, the temperature-programmed desorption (TPD) profiles indicate that $\mathrm{H}_{3} \mathrm{P}^{18} \mathrm{O}$ and $\mathrm{H}_{3} \mathrm{P}^{18} \mathrm{O}_{2}$ oxoacids, which are associated with signal at $\mathrm{m} / z=52$ and 70 , respectively, are formed in both $\mathrm{PH}_{3}-\mathrm{H}_{2}{ }^{18} \mathrm{O}$ and $\mathrm{PH}_{3}-\mathrm{C}^{18} \mathrm{O}_{2}$ systems (Fig. 1). As the irradiation current increases from $100 \mathrm{nA}$ via 1000-5000 nA, the ion counts at $m / z=52\left(\mathrm{H}_{3} \mathrm{P}^{18} \mathrm{O}^{+}\right)$decrease by a factor of about eight in the $\mathrm{PH}_{3}$ $\mathrm{H}_{2}{ }^{18} \mathrm{O}$ system; simultaneously, the signal at $m / z=70\left(\mathrm{H}_{3} \mathrm{P}^{18} \mathrm{O}_{2}{ }^{+}\right)$, which is absent at $100 \mathrm{nA}$, arises. This finding may suggest that phosphinic/hypophosphorous acid $\left(\mathrm{H}_{3} \mathrm{P}^{18} \mathrm{O}_{2}\right)$ is formed from phosphine oxide $\left(\mathrm{H}_{3} \mathrm{P}^{18} \mathrm{O}\right)$ likely via reaction with atomic oxygen. The analysis of the $\mathrm{PH}_{3}-\mathrm{C}^{18} \mathrm{O}_{2}$ systems supports this conclusion: phosphinic/hypophosphorous acid $\left(\mathrm{H}_{3} \mathrm{P}^{18} \mathrm{O}_{2} ; 70 \mathrm{amu}\right)$ is only detected at higher irradiation currents of 1000 and $5000 \mathrm{nA}$. On the other hand, PI-ReTOF-MS did not succeed in the detection of phosphorous/phosphonic acid $\quad\left(\mathrm{H}_{3} \mathrm{P}^{18} \mathrm{O}_{3} ; \quad \mathrm{P}\left({ }^{18} \mathrm{OH}\right)_{3} / \mathrm{HP}^{18} \mathrm{O}\right.$ $\left.\left({ }^{18} \mathrm{OH}\right)_{2}\right)$ or phosphoric acid $\left(\mathrm{H}_{3} \mathrm{P}^{18} \mathrm{O}_{4}\right)$ due to their low volatility that limits their sublimation from the substrate. 


Table 1 Calculated adiabatic ionization energies and relative
energies of various phosphorus oxoacids

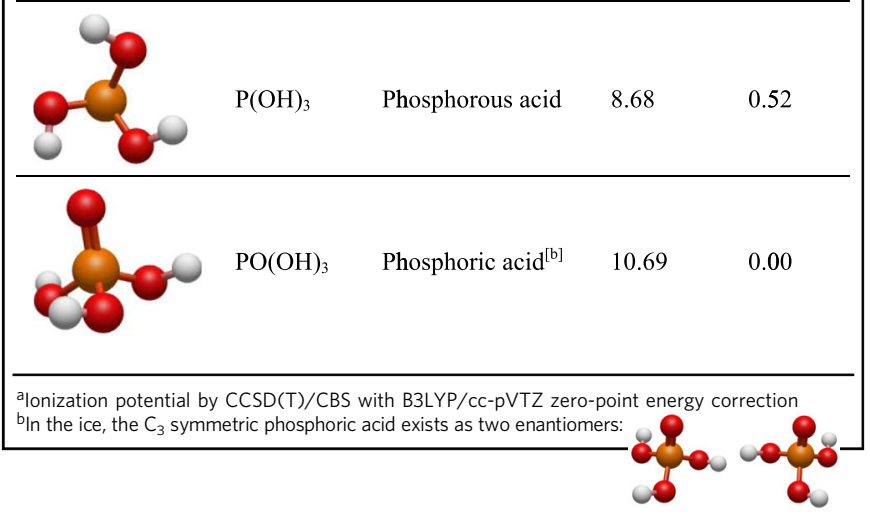

Considering the signals detected at $m / z=52\left(\mathrm{H}_{3} \mathrm{P}^{18} \mathrm{O}^{+}\right)$and $70\left(\mathrm{H}_{3} \mathrm{P}^{18} \mathrm{O}_{2}{ }^{+}\right)$in the $10.86 \mathrm{eV}$ experiment, we were interested in untangling the nature of the structural isomer(s) formed. Since the ionization energies of the $\mathrm{H}_{3} \mathrm{P}^{18} \mathrm{O}-\mathrm{H}_{2} \mathrm{P}^{18} \mathrm{OH}$ and $\mathrm{H}_{2} \mathrm{P}\left({ }^{18} \mathrm{O}\right)$ $\left({ }^{18} \mathrm{OH}\right)-\mathrm{HP}\left({ }^{18} \mathrm{OH}\right)_{2}$ isomer pairs are separated by more than 1.5 $\mathrm{eV}$ (Table 1), a second set of experiments was carried out at a photoionization energy of $9.93 \mathrm{eV}$. This energy is below the ionization energies of the phosphine oxide $\left(\mathrm{H}_{3} \mathrm{P}^{18} \mathrm{O}\right)$ and phosphinic acid $\left(\mathrm{H}_{2} \mathrm{P}\left({ }^{18} \mathrm{O}\right){ }^{18} \mathrm{OH}\right)$ isomers, but above the ionization energies of the hydroxyphosphine $\left(\mathrm{H}_{2} \mathrm{P}^{18} \mathrm{OH}\right)$ and hypophosphorous acid $\left(\mathrm{HP}\left({ }^{18} \mathrm{OH}\right)_{2}\right)$ isomers. A close inspection of the TPD profiles of $m / z=52$ (Fig. 1) reveals that the TPD profiles are nearly identical at 10.86 and $9.93 \mathrm{eV}$, suggesting that at least the thermodynamically less stable hydroxyphosphine isomer $\left(\mathrm{H}_{2} \mathrm{P}^{18} \mathrm{OH}\right)$ is formed; since the absolute photoionization cross-sections of both isomers are unknown, the presence of phosphine oxide cannot be proven. However, Withnall and Andrews explored in previous matrix isolation experiments the chemistry of phosphine-molecular oxygen samples ${ }^{26,27}$ and revealed the formation of hydroxyphosphine $\left(\mathrm{H}_{2} \mathrm{POH}\right)$ with smaller contributions of the phosphine oxide isomer $\left(\mathrm{H}_{3} \mathrm{PO}\right)$. Finally, we compare the TPD profiles of $m / z=70$ recorded at 10.86 and $9.93 \mathrm{eV}$. Upon lowering the photon energy to $9.93 \mathrm{eV}$, the signal at $m / z=70$ vanishes; therefore, we can conclude that only the thermodynamically preferred phosphinic acid isomer $\left(\mathrm{H}_{2} \mathrm{P}\left({ }^{18} \mathrm{O}\right)^{18} \mathrm{OH}\right)$ is formed, but no hypophosphorous acid (HP $\left.\left({ }^{18} \mathrm{OH}\right)_{2}\right)$. The higher molecular weight of phosphinic acid (70 $\mathrm{amu}$ ) compared to hydroxyphosphine (52 amu) is also associated with an increase of the sublimation temperature in the range of $260-300 \mathrm{~K}$ in contrast to $160-240 \mathrm{~K}$.

TOF-SIMS. Having established the synthesis of at least two of the simplest phosphorus oxoacids (hydroxyphosphine and phosphinic acid) and possibly phosphine oxide by exploiting PIReTOF-MS, we searched for higher molecular-weight oxoacids in the residues of the annealed samples utilizing time-of-flight secondary ion mass spectrometry (TOF-SIMS). TOF-SIMS facilitates the sputtering of the solid residues and detects the ions in both positive and negative ion detection modes (Fig. 2). Since the sputtering might also fragment the phosphorus oxoacids, these fragmentation patterns have to be determined. This assists in an identification of well-defined mass-to-charge ratios unique to each of the oxoacids and also allows a quantification of the oxoacids formed. The results of the calibration of phosphonic acid $\left(\mathrm{H}_{3} \mathrm{PO}_{3}\right)$, phosphoric acid $\left(\mathrm{H}_{3} \mathrm{PO}_{4}\right)$, and pyrophosphoric acid $\left(\mathrm{H}_{4} \mathrm{P}_{2} \mathrm{O}_{7}\right)$ are compiled in Supplementary Tables 3 and 4. The negative ion spectra are very sensitive to probe the oxoacids via their deprotonated parent molecules. Here, pyrophosphoric $\left(\mathrm{H}_{4} \mathrm{P}_{2}{ }^{18} \mathrm{O}_{7}\right)$ and phosphonic acid $\left(\mathrm{H}_{3} \mathrm{P}^{18} \mathrm{O}_{3}\right)$ can be identified in all residues via their unique signals of $\mathrm{HP}_{2}{ }^{18} \mathrm{O}_{6}{ }^{-} / \mathrm{H}_{3} \mathrm{P}_{2}{ }^{18} \mathrm{O}_{7}{ }^{-}$and $\mathrm{H}_{2} \mathrm{P}^{18} \mathrm{O}_{3}{ }^{-}$, respectively. While pyrophosphoric acid has a fragment of small intensity for $\mathrm{H}_{2} \mathrm{P}^{18} \mathrm{O}_{4}{ }^{-}$, the low quantity of $\mathrm{H}_{4} \mathrm{P}_{2}{ }^{18} \mathrm{O}_{7}$ in our residues contributes a minor amount to the moderately intense $\mathrm{H}_{2} \mathrm{P}^{18} \mathrm{O}_{4}{ }^{-}$signal, which can be attributed to phosphoric acid $\left(\mathrm{H}_{3} \mathrm{P}^{18} \mathrm{O}_{4}\right)$. As a general trend, the yield of each of these oxoacids increases with the irradiation dose; significantly enhanced yields are seen in carbon dioxide bearing ices compared to water-rich ices especially at higher doses. Although phosphinic acid is subliming at $260-300 \mathrm{~K}$ as verified in the PI-ReTOF-MS analysis, the SIMS analysis revealed a strong peak for $\mathrm{H}_{2} \mathrm{P}^{18} \mathrm{O}_{2}{ }^{-}$; this ion is not observed as a fragment from any calibration compound, but can be formally linked to phosphinic acid $\left(\mathrm{H}_{3} \mathrm{P}^{18} \mathrm{O}_{2}\right)$. A close look at the PI-ReTOF-MS data (Fig. 1) indicates that the intensity of $m / z=70\left(\mathrm{H}_{3} \mathrm{P}^{18} \mathrm{O}_{2}{ }^{+}\right)$does not completely lead to zero at $300 \mathrm{~K}$; therefore, a fraction of phosphinic acid $\left(\mathrm{H}_{3} \mathrm{P}^{18} \mathrm{O}_{2}\right)$ is likely to reside in the solid residue. Although holding a lower sensitivity, the positive ion spectra confirm the assignments derived from the negative ion mode. Pyrophosphoric acid $\left(\mathrm{H}_{4} \mathrm{P}_{2}{ }^{18} \mathrm{O}_{7}\right)$, phosphonic acid $\left(\mathrm{H}_{3} \mathrm{P}^{18} \mathrm{O}_{3}\right)$, and phosphoric acid $\left(\mathrm{H}_{3} \mathrm{P}^{18} \mathrm{O}_{4}\right)$ could be detected via their protonated counterparts, i.e., $\mathrm{H}_{5} \mathrm{P}_{2}{ }^{18} \mathrm{O}_{7}{ }^{+}, \mathrm{H}_{4} \mathrm{P}^{18} \mathrm{O}_{3}{ }^{+}$, and $\mathrm{H}_{4} \mathrm{P}^{18} \mathrm{O}_{4}{ }^{+}$.

Gas chromatography. Finally, the phosphorus oxoacids in the residues were also extracted, derivatized as trimethylsilyl (TMS) esters $\left(-\mathrm{OSi}\left(\mathrm{CH}_{3}\right)_{3}\right)$, and analyzed via two-dimensional gas chromatography time-of-flight mass spectrometry. A TOF-MS was exploited to record the retention times along with the mass spectra (Supplementary Table 5). This protocol led to the detection of three 

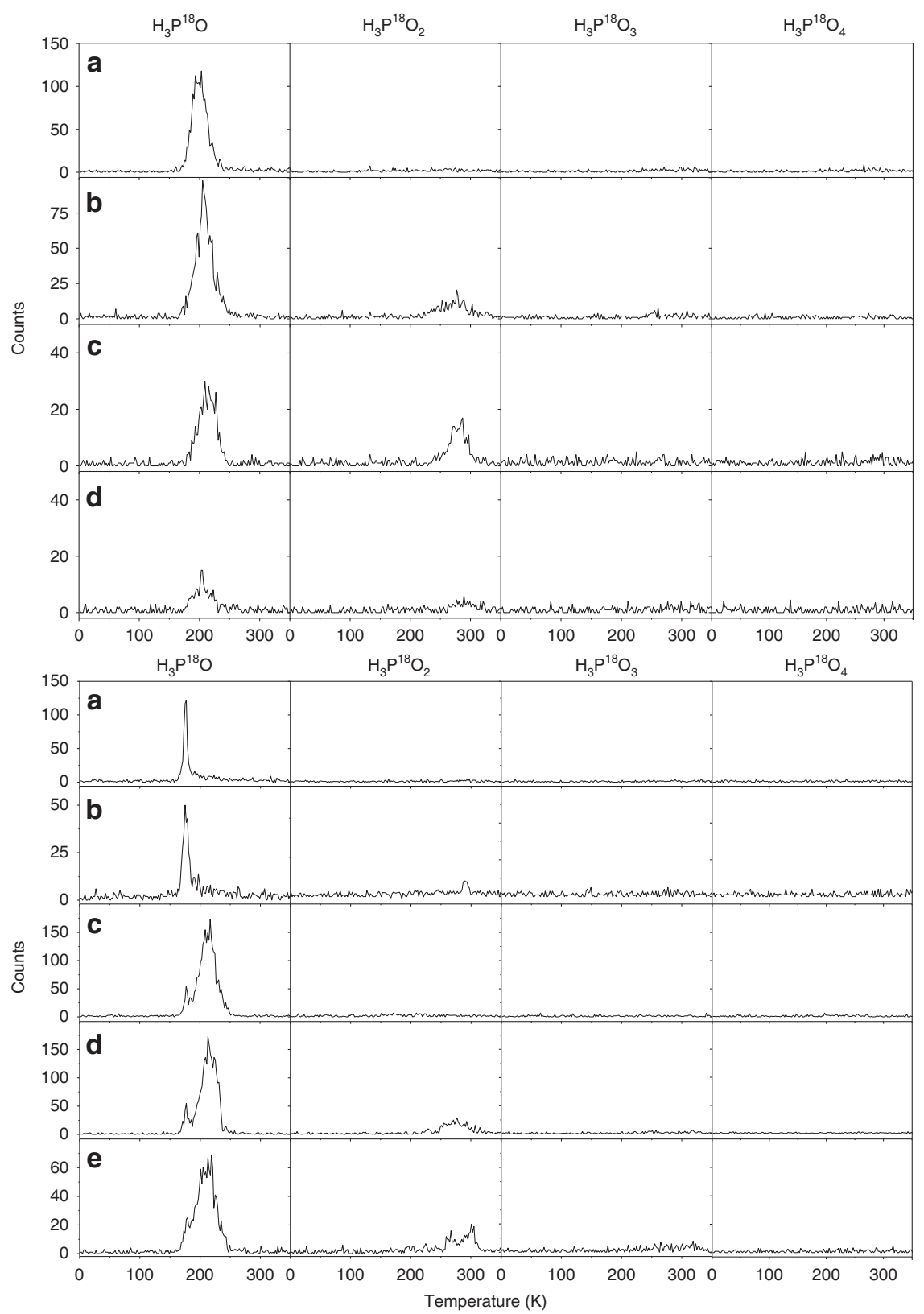

Fig. $1 \mathrm{PI}$-ReTOF-MS data showing the temperature-programmed desorption profiles for phosphorus oxoacids. Each column displays the profiles for $m / z=$ $52\left(\mathrm{H}_{3} \mathrm{P}^{18} \mathrm{O}\right), \mathrm{m} / z=70\left(\mathrm{H}_{3} \mathrm{P}^{18} \mathrm{O}_{2}\right), \mathrm{m} / z=88\left(\mathrm{H}_{3} \mathrm{P}^{18} \mathrm{O}_{3}\right)$, and $\mathrm{m} / z=106\left(\mathrm{H}_{3} \mathrm{P}^{18} \mathrm{O}_{4}\right)$. Top: Ices of phosphine $\left(\mathrm{PH}_{3}\right)$-carbon dioxide $\left(\mathrm{C}^{18} \mathrm{O}_{2}\right)$ at irradiation currents of a $100 \mathrm{nA}, 9.93 \mathrm{eV}$ photoionization energy, b $100 \mathrm{nA}, 10.86 \mathrm{eV}$ photoionization energy, c $1000 \mathrm{nA}, 10.86 \mathrm{eV}$ photoionization energy, and d $5000 \mathrm{nA}, 10.86 \mathrm{eV}$ photoionization energy. Bottom: Ices of phosphine $\left(\mathrm{PH}_{3}\right)$-water $\left(\mathrm{H}_{2}{ }^{18} \mathrm{O}\right)$ at irradiation currents of a $100 \mathrm{nA}, 9.93 \mathrm{eV}$ photoionization energy, b $100 \mathrm{nA}, 10.86 \mathrm{eV}$ photoionization energy, c $1000 \mathrm{nA}, 9.93 \mathrm{eV}$ photoionization energy, d $1000 \mathrm{nA}, 10.86 \mathrm{eV}$ photoionization energy, and e 5000 $\mathrm{nA}, 10.86 \mathrm{eV}$ photoionization energy. The PI-ReTOF-MS data for the blank experiments are shown in Supplementary Fig. 2

phosphorus oxoacids (Fig. 3): phosphoric acid $\left(\mathrm{H}_{3} \mathrm{P}^{18} \mathrm{O}_{4}\right)$, phosphonic acid $\left(\mathrm{HP}^{18} \mathrm{O}\left({ }^{18} \mathrm{OH}\right)_{2}\right)$, and phosphinic acid $\left(\mathrm{H}_{2} \mathrm{P}^{18} \mathrm{O}\left({ }^{18} \mathrm{OH}\right)\right)$. Phosphoric acid could be identified via the molecular ion of the tris (trimethylsilyl)ester $\left({ }^{18} \mathrm{OP}\left({ }^{18} \mathrm{Osi}\left(\mathrm{CH}_{3}\right)_{3}\right)_{3}\right)$ at $\mathrm{m} / z\left(\mathrm{M}^{+}\right)=322$ and its fragment originating from the loss of a methyl group at $m / z\left(\mathrm{M}^{+}\right.$ $-15)=307^{29}$. Phosphonic acid was detected via the molecular ion of the derivatized phosphorous acid tautomer in the form of its tris (trimethylsilyl)ester $\left(\mathrm{P}\left({ }^{18} \mathrm{OSi}\left(\mathrm{CH}_{3}\right)_{3}\right)_{3}\right)$ at $\mathrm{m} / z\left(\mathrm{M}^{+}\right)=304$ and its fragment of the methyl group loss at $m / z\left(\mathrm{M}^{+}-15\right)=304^{30}$. Finally, phosphinic acid could be sampled via its hypophosphorous acid tautomer as its bis(trimethylsilyl)ester $\left(\mathrm{HP}\left({ }^{18} \mathrm{OSi}\left(\mathrm{CH}_{3}\right)_{3}\right)_{2}\right)$ at $m / z(\mathrm{M}$ $\left.{ }^{+}\right)=214$ and also by its fragment of the methyl group elimination at $\mathrm{m} / z \quad\left(\mathrm{M}^{+}-15\right)=199$. Derivatization as trimethylsilyl
(TMS) esters shifts the tautomeric phosphonic-phosphorous and phosphinic-hypophosphorous acid equilibrium to the phosphorous

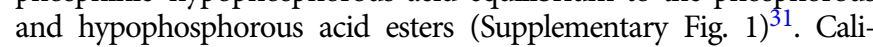
bration experiments suggest that the TMS derivative of pyrophosphoric acid as detected in small quantities via SIMS was found to be thermally unstable and decomposed on the GC columns ${ }^{32}$. Consequently, with the exception of pyrophosphoric acid, the GC×GCTOF-MS analysis correlates exceptionally well with the SIMS data that detected key phosphorus oxoacids in the residues of the irradiated phosphine-doped interstellar analog ices.

Discussion. Having identified four monophosphorus oxoacids [hydroxyphosphine $\left(\mathrm{H}_{3} \mathrm{PO}: \mathrm{PH}_{2} \mathrm{OH}(-\mathrm{I})\right)$, phosphinic acid 
$\left(\mathrm{H}_{3} \mathrm{PO}_{2}: \mathrm{H}_{2} \mathrm{P}(\mathrm{O}) \mathrm{OH}(+\mathrm{I})\right)$, phosphonic acid $\left(\mathrm{H}_{3} \mathrm{PO}_{3}: \mathrm{HP}(\mathrm{O})\right.$ $(\mathrm{OH})_{2}(+\mathrm{III})$ ), phosphoric acid (phosphoric acid $\left(\mathrm{H}_{3} \mathrm{PO}_{4}(+\mathrm{V})\right)$ ] along with pyrophosphoric acid $\left(\mathrm{H}_{4} \mathrm{P}_{2} \mathrm{O}_{7}(+\mathrm{V})\right)$ with phosphorus in four distinct oxidation states ranging from $-\mathrm{I}$ to $+\mathrm{V}$, we are discussing now possible formation pathways. For simplicity in the following discussion, the ${ }^{18} \mathrm{O}$ label is dropped. It should be noted that although the FTIR analysis provided evidence on the emergence of functional groups associated with phosphorus oxoacids even at $5 \mathrm{~K}$, the FTIR data were unable to identify individual oxoacids due to overlapping absorptions of the functional groups. Therefore, kinetic profiles linked to the formation of individual phosphorus oxoacids could not be provided. However, a few important conclusions can be drawn. First, based on the PIReTOF-MS data recorded at 100,1000, and $5000 \mathrm{nA}$, the yields of $\mathrm{PH}_{2} \mathrm{OH}(-\mathrm{I})$ and $\mathrm{H}_{2} \mathrm{P}(\mathrm{O}) \mathrm{OH}(+\mathrm{I})$ depend on the irradiation current and hence dose. Recall that in the $\mathrm{PH}_{3}-\mathrm{H}_{2} \mathrm{O}$ system, $\mathrm{H}_{2} \mathrm{P}$ $(\mathrm{O}) \mathrm{OH}(+\mathrm{I})$ is absent in the $100 \mathrm{nA}$ experiment, but emerges at $1000 \mathrm{nA}$. This observation suggests a sequential formation of phosphorus oxoacids via stepwise reaction of oxygen atoms starting with phosphine $\left(\mathrm{PH}_{3}\right)$. Considering the water- and carbon dioxide-rich ices, the radiolysis of water and carbon dioxide can generate electronically excited oxygen atoms in strongly endoergic reactions ${ }^{5,33-35}$; water can also decompose via the formation of atomic hydrogen and hydroxyl radicals $(\mathrm{OH})(\mathrm{Eq} .1-3)$. The required energy for the bond dissociation can be supplied by the energetic electrons.

$$
\begin{aligned}
& \mathrm{CO}_{2}\left(X^{1} \Sigma_{g}^{+}\right) \rightarrow \mathrm{CO}\left(X^{1} \Sigma^{+}\right)+\mathrm{O}\left({ }^{1} D\right) \Delta_{\mathrm{R}} \mathrm{G}=7.59 \mathrm{eV} \\
& \mathrm{H}_{2} \mathrm{O}\left(X^{1} \mathrm{~A}_{1}\right) \rightarrow \mathrm{H}\left({ }^{2} \mathrm{~S}\right)+\mathrm{OH}\left(X^{2} \Pi_{\Omega}\right) \Delta_{\mathrm{R}} \mathrm{G}=4.83 \mathrm{eV} \\
& \mathrm{H}_{2} \mathrm{O}\left(X^{1} \mathrm{~A}_{1}\right) \rightarrow \mathrm{H}_{2}\left(X^{1} \Sigma_{g}^{+}\right)+\mathrm{O}\left({ }^{1} D\right) \Delta_{\mathrm{R}} \mathrm{G}=6.74 \mathrm{eV}
\end{aligned}
$$

Simultaneously, the energetic electrons can also lead to a phosphorus-hydrogen bond rupture in phosphine leading to phosphino $\left(\mathrm{PH}_{2}\right)$ radicals (Eq. 4$)^{36}$.

$$
\mathrm{PH}_{3}\left(X^{1} \mathrm{~A}_{1}\right) \rightarrow \mathrm{PH}_{2}\left(X^{2} \mathrm{~B}_{1}\right)+\mathrm{H}\left({ }^{2} \mathrm{~S}\right) \Delta_{\mathrm{R}} \mathrm{G}=3.51 \mathrm{eV}
$$

In the water-phosphine system, the formation of $\mathrm{PH}_{2} \mathrm{OH}$ may proceed via a barrier-less recombination of the phosphino $\left(\mathrm{PH}_{2}\right)$ radical with the hydroxyl (OH) radical (Eq. 5). Alternatively, electronically excited oxygen atoms can insert without barrier into the phosphorus-hydrogen bond leading to $\mathrm{PH}_{2} \mathrm{OH}$ as well (Eq. 6). It is important to note that electronically excited oxygen atoms can also add without barrier to the phosphorus atom of phosphine yielding phosphine oxide $\left(\mathrm{H}_{3} \mathrm{PO}\right)$ (Eq. 7), which can then undergo hydrogen migration to form $\mathrm{PH}_{2} \mathrm{OH}^{26,27,37}$. Schmidt et al. suggested that a barrier between 3.01 and $3.73 \mathrm{eV}$ separated both isomers ${ }^{38}$; this energy can be supplied by the energetic electrons as well. Recall that the formation of phosphine oxide could not be proven or disproven in our study. We would like to stress that Stief et al. also probed the gas phase kinetics of ground-state atomic oxygen with phosphine over a temperature range of 208-423 K revealing that ground-state oxygen preferentially adds to the phosphorus atom ${ }^{39,40}$; unfortunately, neither products were identified, nor the role of intersystem crossing from the triplet to the singlet surface were probed.

$$
\mathrm{PH}_{2}\left(X^{2} \mathrm{~B}_{1}\right)+\mathrm{OH}\left(X^{2} \Pi_{\Omega}\right) \rightarrow \mathrm{PH}_{2} \mathrm{OH}\left(X^{1} A^{\prime}\right) \Delta_{\mathrm{R}} \mathrm{G}=-5.27 \mathrm{eV}
$$

$$
\begin{gathered}
\mathrm{PH}_{3}\left(X^{1} \mathrm{~A}_{1}\right)+\mathrm{O}\left({ }^{1} D\right) \rightarrow \mathrm{PH}_{2} \mathrm{OH}\left(X^{1} A^{\prime}\right) \Delta_{\mathrm{R}} \mathrm{G}=-8.27 \mathrm{eV} \\
\mathrm{H}_{3} \mathrm{PO}\left(X^{1} \mathrm{~A}_{1}\right) \rightarrow \mathrm{PH}_{2} \mathrm{OH}\left(X^{1} A^{\prime}\right) \Delta_{\mathrm{R}} \mathrm{G}=0.03 \mathrm{eV}
\end{gathered}
$$

Once $\mathrm{PH}_{2} \mathrm{OH}$ is formed, the addition of another electronically excited oxygen atom to the phosphorus atom produces $\mathrm{H}_{2} \mathrm{P}(\mathrm{O})$ $\mathrm{OH}$ (Eq. 8). Successive insertions of electronically excited oxygen atoms in phosphorus-hydrogen bonds may lead via $\mathrm{HP}(\mathrm{O})(\mathrm{OH})_{2}$ (Eq. 9) to $\mathrm{H}_{3} \mathrm{PO}_{4}$ (Eq. 10). Essentially, in this reaction sequence, up to four oxygen atoms are required to oxidize phosphine to ultimately phosphoric acid via stepwise oxidation. The release of up to four oxygen atoms requires $27.0 \mathrm{eV}$ and $30.4 \mathrm{eV}$ to be generated from water and carbon dioxide, respectively. Therefore, thermal reactions cannot lead to the oxoacids at $5 \mathrm{~K}$, but cosmicray-triggered non-equilibrium chemistry is required to supply the required oxygen atoms (and possibly the hydroxyl radicals) for the oxidation process.

$$
\begin{gathered}
\mathrm{PH}_{2} \mathrm{OH}\left(X^{1} \mathrm{~A}^{\prime}\right)+\mathrm{O}\left({ }^{1} \mathrm{D}\right) \rightarrow \\
\mathrm{H}_{2} \mathrm{P}(\mathrm{O}) \mathrm{OH}\left(X^{1} \mathrm{~A}^{\prime}\right) \Delta_{\mathrm{R}} \mathrm{G}=-7.68 \mathrm{eV} \\
\mathrm{H}_{2} \mathrm{P}(\mathrm{O}) \mathrm{OH}\left(X^{1} \mathrm{~A}^{\prime}\right)+\mathrm{O}\left({ }^{1} \mathrm{D}\right) \rightarrow \\
\mathrm{H}_{2} \mathrm{P}(\mathrm{O})(\mathrm{OH})_{2}\left(X^{1} \mathrm{~A}^{\prime}\right) \Delta_{\mathrm{R}} \mathrm{G}=-7.81 \mathrm{eV} \\
\mathrm{H}_{2} \mathrm{P}(\mathrm{O})(\mathrm{OH})_{2}\left(X^{1} \mathrm{~A}^{\prime}\right)+\mathrm{O}\left({ }^{1} \mathrm{D}\right) \rightarrow \\
\mathrm{H}_{3} \mathrm{PO}_{4}\left(X^{1} \mathrm{~A}\right) \Delta_{\mathrm{R}} \mathrm{G}=-7.62 \mathrm{eV}
\end{gathered}
$$

In regard to the conversion yields, the infrared analysis indicates that $76 \pm 8 \%$ of the phosphine reacted in the $10: 1 \mathrm{CO}_{2}$ : $\mathrm{PH}_{3}$ ice; this was determined by utilizing the comparative area of the $v_{2}$ and $v_{4}$ bands of phosphine. Similarly, the $v_{2}, 2 v_{2}+v_{3}$, and $v_{1}+v_{3}$ bands of carbon dioxide show that $28 \pm 1 \%$ of $\mathrm{CO}_{2}$ was destroyed after the irradiation. This equates to $8 \pm 2 \times 10^{16}$ molecules of phosphine and $3 \pm 1 \times 10^{17}$ molecules of carbon dioxide destroyed by irradiation. Since each irradiated carbon dioxide molecule liberates only one oxygen atom, the ratio of available reactive phosphorus-to-oxygen atoms is thus 1.0:3.4 \pm 0.8 . If all of the reacted phosphine became incorporated into one of the three simplest oxoacids, the $8 \pm 2 \times 10^{16}$ molecules produced suggest that $2.1 \pm 0.8 \times 10^{-4}$ molecules were formed per $\mathrm{eV}$ of irradiation. The formation of $\mathrm{H}_{3} \mathrm{PO}_{4}$ is limited by the number of oxygen atoms generated, and at most $7 \pm 2 \times 10^{16}$ molecules of $\mathrm{H}_{3} \mathrm{PO}_{4}$ could form, which corresponds to a generation of $1.7 \pm 0.6 \times 10^{-4} \mathrm{H}_{3} \mathrm{PO}_{4}$ molecules $\mathrm{eV}^{-1}$. The $v_{2}$ and $v_{\mathrm{L}}$ bands of water were analyzed for the $10: 1 \mathrm{H}_{2} \mathrm{O}: \mathrm{PH}_{3}$ ice, and $62 \pm 2 \%$ of phosphine was found to have reacted, while only $37 \pm 5 \%$ of the water was destroyed. This is equivalent to $6 \pm 2 \times$ $10^{16}$ phosphine molecules and $8 \pm 3 \times 10^{17}$ water molecules. In this case, much more oxygen was available compared to phosphorus, with a 1:12 phosphorus-to-oxygen atom ratio, and thus phosphorus will always be the limiting atom in the formation of the oxoacids. Here, the upper yields of $6 \pm 2 \times 10^{16}$ molecules of phosphorus oxoacids are formed at $1.6 \pm 0.6 \times 10^{-4}$ molecules $\mathrm{eV}^{-1}$.

Using reagent standards, the quantity of phosphoric acid $\left(\mathrm{H}_{3} \mathrm{PO}_{4}\right)$ in the residues can be determined via GC $\times$ GC-TOF-MS and compared to the infrared spectra to establish a reaction yield. 

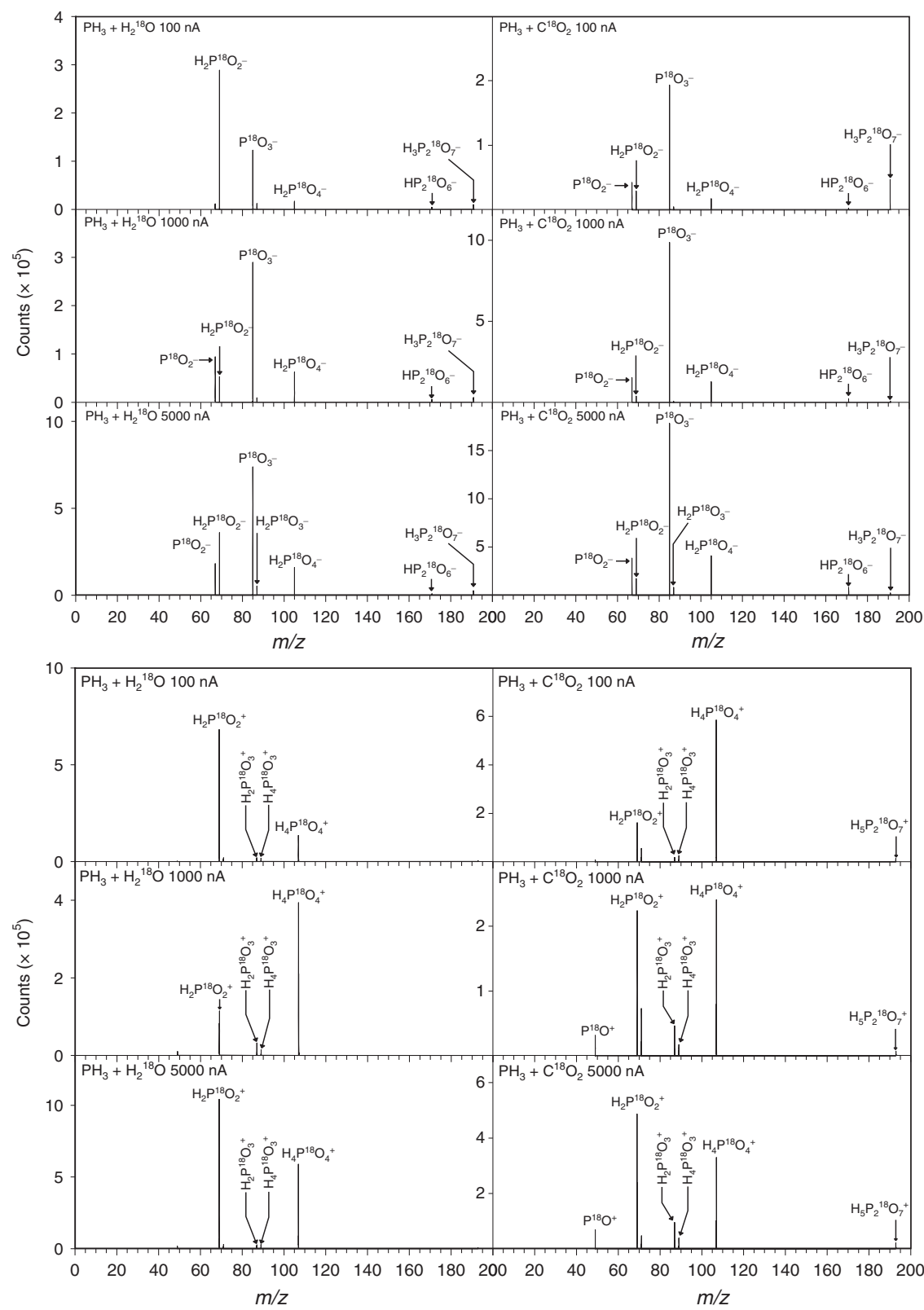

Fig. 2 SIMS data from residues of irradiated phosphine-doped ices. The spectra were recorded in the negative (top) and positive ion mode (bottom) correlated with the formation of ${ }^{18} \mathrm{O}$-substituted oxoacids formed in irradiated phosphine $\left(\mathrm{PH}_{3}\right)$-water $\left(\mathrm{H}_{2}{ }^{18} \mathrm{O}\right)$ (right) and phosphine $\left(\mathrm{PH}_{3}\right)$-carbon dioxide $\left(\mathrm{C}^{18} \mathrm{O}_{2}\right)$ (left) ices

The $\mathrm{CO}_{2}: \mathrm{PH}_{3}$ ices produced $5 \mathrm{nmol}\left(3 \times 10^{15}\right.$ molecules $)$ of phosphoric acid, while only $1 \mathrm{nmol}\left(6 \times 10^{14}\right.$ molecules $)$ was detected from the $\mathrm{H}_{2} \mathrm{O}: \mathrm{PH}_{3}$ ice, which results in $7 \pm 3 \times 10^{-6}$ molecules of $\mathrm{H}_{3} \mathrm{PO}_{4}$ per eV in the $\mathrm{CO}_{2}: \mathrm{PH}_{3}$ ice and $2 \pm 1 \times 10^{-6}$ $\mathrm{H}_{3} \mathrm{PO}_{4}$ molecules $\mathrm{eV}^{-1}$ in the $\mathrm{H}_{2} \mathrm{O}: \mathrm{PH}_{3}$ ice. Thus, phosphoric acid represents $4 \%$ of the reacted phosphine in $\mathrm{CO}_{2}: \mathrm{PH}_{3}$, while a $1 \%$ yield was found in the $\mathrm{H}_{2} \mathrm{O}: \mathrm{PH}_{3}$ system. As phosphoric acid was the most abundant compound detected in the residues, this indicates that most of the phosphorus sublimed during the TPD, for example, as diphosphane as detected experimentally.

In conclusion, by exposing phosphine $\left(\mathrm{PH}_{3}\right)$-doped interstellar analog ices to ionization radiation and exploiting an array of complementary in situ and ex situ analytical tools, the present study offers compelling evidence on a facile formation of distinct oxoacids of phosphorus: phosphinic acid $\left(\mathrm{H}_{3} \mathrm{PO}_{2}\right) \mathrm{P}(\mathrm{I})$, phosphonic acid $\left(\mathrm{H}_{3} \mathrm{PO}_{3}\right) \mathrm{P}(\mathrm{III})$, phosphoric acid $\left(\mathrm{H}_{3} \mathrm{PO}_{4}\right) \mathrm{P}(\mathrm{V})$, and pyrophosphoric acid $\left(\mathrm{H}_{4} \mathrm{P}_{2} \mathrm{O}_{7}\right) \mathrm{P}(\mathrm{V})$. The formation of those oxoacids can be initiated via a radical-radical recombination between the hydroxy $(\mathrm{OH})$ and phosphino $\left(\mathrm{PH}_{2}\right)$ radicals (Eq. 5) or through insertion of electronically excited atomic oxygen, released by unimolecular decomposition of water and carbon dioxide, with phosphine-forming phosphinic acid $\left(\mathrm{PH}_{2} \mathrm{OH}\right)$ (Eq. 6). Once phosphinic acid $\left(\mathrm{PH}_{2} \mathrm{OH}\right)$ forms, successive addition and insertion of electronically excited oxygen atom to the phosphorus atom produce phosphonic acid $\left(\mathrm{H}_{3} \mathrm{PO}_{3}\right)$ and phosphoric acid $\left(\mathrm{H}_{3} \mathrm{PO}_{4}\right)$ (reactions 8-10). Overall, up to four oxygen atoms are needed to oxidize phosphine to phosphoric acid; this requires up to about $30 \mathrm{eV}$. Hence, thermal reactions cannot form oxoacids at $5 \mathrm{~K}$, but cosmic-ray-triggered nonequilibrium chemistry is required to supply the required oxygen atoms (and possibly the hydroxyl radicals) for the oxidation process. Please note that our studies were carried out in the condensed (ice) phase, but not under single collision conditions in the gas phase ${ }^{41}$. Therefore, it is not feasible neither in the 


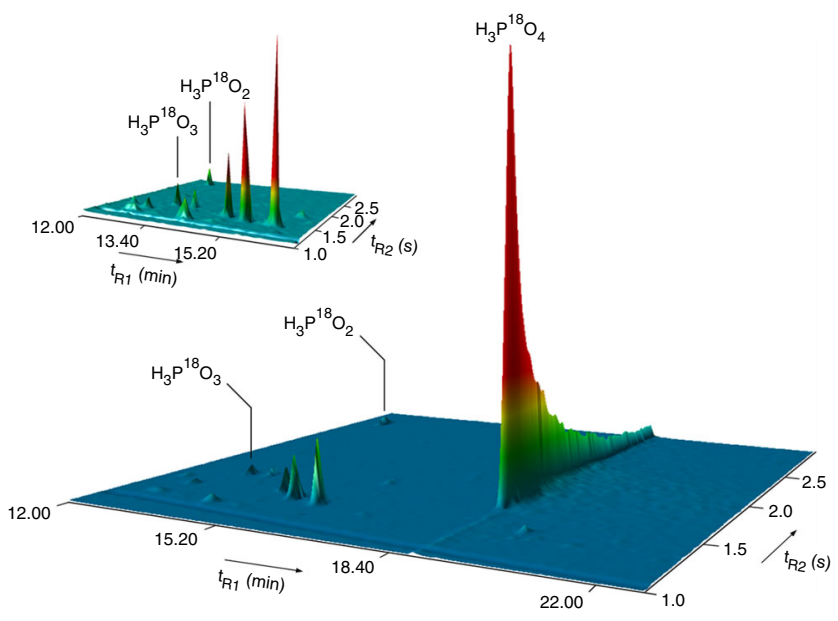

Fig. 3 Multidimensional gas chromatogram showing ${ }^{18} \mathrm{O}$-labeled phosphorus oxoacids extracted from the residues. The atomic mass units $214(\times 100)$ and $304(\times 150)$ were selected for this multidimensional chromatographic representation. Partial GC $\times \mathrm{GC}$ chromatogram of the separation of the two minor phosphorus oxoacids is shown top left. The unassigned peaks result from the silylation agent (BSTFA: TMCS 1\%) that was injected in excess compared to the blank analysis (Supplementary Fig. 3) to avoid sample loss

present studies nor in any other laboratory to determine the efficiency of each elementary reaction (oxidation step) involved in the formation of the individual oxoacids. This would require pulse-probe experiments with femtosecond (few $10 \mathrm{fs}$ pulses) electron pulses penetrating the ice sample. These experiments do not exist yet.

Whereas on Earth, phosphine is classified as highly toxic and only slightly soluble in water, the present work reveals interstellar phosphine as a critical precursor in the synthesis of highly watersoluble phosphorus oxoacids prevalent in contemporary biochemistry. Phosphoric acid $\left(\mathrm{H}_{3} \mathrm{PO}_{4}\right)$ in particular presents a soluble source of phosphorus in the phosphorus $(\mathrm{V})$ oxidation state as found in RNA/DNA and ADP/ATP. The identification of pyrophosphoric acid $\left(\mathrm{H}_{4} \mathrm{P}_{2} \mathrm{O}_{7}\right)$ - a formal condensation product of phosphoric acid-is significant since our investigations expose that polyphosphates such as diphosphates found in ADP can be formed in interstellar ices upon interaction with ionizing radiation mimicking typical life times of molecular clouds of a few $10^{6}$ years. The unsuccessful detection of triphosphoric acid $\left(\mathrm{H}_{5} \mathrm{P}_{3} \mathrm{O}_{10}\right)$-a precursor to the phosphorus backbone of ATP-could indicate that the phosphorus chemistry in interstellar ices ceases with the synthesis of pyrophosphoric acid over the lifetime of a molecular cloud, thus defining the molecular complexity of phosphorusbearing oxoacids formed in extraterrestrial environments.

Finally, the synthesis of phosphonic acid $\left(\mathrm{H}_{3} \mathrm{PO}_{3}\right)$ could support an alternative route to phosphorus (III) as found in alkylphosphonic acids in the Murchison meteorite. As these alkylphosphonic acids are of continued interest to the "Origins of Life" community, the incorporation of methane $\left(\mathrm{CH}_{4}\right)$ or more complex hydrocarbons to interstellar ices has the potential to yield a complex mixture of alkylphosphonic acids as detected in Murchison and, with derivatives of phosphoric acid, biologically relevant phosphate esters. While other interstellar phosphorusbearing molecules, such $\mathrm{CP}$ or $\mathrm{HCP}^{42}$, have been considered as a source of phosphorus for alkylphosphonic acids via gas or aqueous phase reactions, phosphine $\left(\mathrm{PH}_{3}\right)$ represents the ideal compound for phosphorus-based interstellar ice experiments, which has been a missing piece in the astrochemical-phosphorus literature that is rich with gas and mineral phase studies. The phosphorus oxoacids detected in our experiments might have also been formed within the ices of comets such as 67P/ChuryumovGerasimenko, whose phosphorus source is believed to derive from phosphine ${ }^{16}$. Since comets contain at least partially the remnants of the material of the protoplanetary disk that formed our Solar System, these compounds might be traced back to the interstellar medium wherever sufficient phosphine in interstellar ices is available. Upon delivery to Earth by meteorites or comets, these phosphorus oxoacids would have been available for Earth's prebiotic phosphorus chemistry. For example, recent studies have shown phosphoric acid ${ }^{43}$ and diamidophosphate-a possible derivative of trimetaphosphate ${ }^{44}$-can abiotically phosphorylate various prebiotic compounds such as sugars, amino acids, and nucleotides in aqueous solution to produce higher-order biologically relevant molecules. Although future studies have to be conducted on the underlying formation mechanisms of these oxoacids, the present study embodies a step toward elucidating possible abiotic pathways toward oxoacids of phosphorus resembling key molecular building blocks in contemporary biochemistry on Earth thus bringing us closer to eventually predicting where in the galaxy molecular precursors linked to the origins of life might have been synthesized.

\section{Methods}

Experimental. Ices of phosphine (99.9995\%), carbon dioxide (99.999\%), and water (HPLC grade), along with oxygen-18-labeled carbon dioxide (95 atom $\%{ }^{18} \mathrm{O}$ ) and water $\left(99\right.$ atom $\left.\%{ }^{18} \mathrm{O}\right)$, were deposited onto a polished silver wafer. This silver substrate was mounted onto an oxygen-free high-conductivity copper cold head capable of achieving temperatures as low as $5 \mathrm{~K}$ by a closed-cycle helium refrigerator (Sumitomo Heavy Industries, RDK-415E) inside a contamination-free stainless steel chamber capable of pressures down to $5 \times 10^{-11}$ Torr using magnetically suspended turbomolecular pumps (Osaka) and oil-free backing pumps (Anest Iwata) ${ }^{45}$. Phosphine and carbon dioxide gases were premixed and deposited at $2 \times 10^{-8}$ Torr via a glass capillary, while phosphine and water were deposited simultaneously using separate transfer mechanisms to avoid any pre-deposition reactions. Deposition continued until $750 \mathrm{~nm}$ of ice was deposited, which was measured in situ using laser interferometry by monitoring the interference fringes of a helium-neon laser $(632.8 \mathrm{~nm})$ that is reflected off the silver substrate ${ }^{46}$. The ice mixtures were found to be 10:1 water to phosphine and carbon dioxide to phosphine by using integrated infrared absorption coefficients ${ }^{47}$. The refractive index of the ice mixture, which is necessary for the thickness calculation, was determined to be the refractive index of the matrix $\left(n_{\mathrm{CO}_{2}}=1.27^{47}, n_{\mathrm{H}_{2} \mathrm{O}}=1.29^{48}\right)$. The ices were irradiated with $5 \mathrm{keV}$ electrons at a $70^{\circ}$ angle to the surface normal for $1 \mathrm{~h}$ at currents of 100,1000 , and $5000 \mathrm{nA}$. Exploiting the CASINO simulation ${ }^{49}$, the average penetration depth was found to be $285 \mathrm{~nm}\left(\mathrm{H}_{2} \mathrm{O} / \mathrm{PH}_{3}\right)$ and $300 \mathrm{~nm}\left(\mathrm{CO}_{2} /\right.$ $\left.\mathrm{PH}_{3}\right)$, while the maximum penetration depth was $650 \mathrm{~nm}\left(\mathrm{H}_{2} \mathrm{O} / \mathrm{PH}_{3}\right)$ and $700 \mathrm{~nm}$ $\left(\mathrm{CO}_{2} / \mathrm{PH}_{3}\right)$, which is less than the $750 \mathrm{~nm}$ ice thickness. The average dose was calculated to be $2.8 \pm 0.6 \mathrm{eV}$ per molecule $\left(\mathrm{CO}_{2} / \mathrm{PH}_{3}\right)$ and $2.4 \pm 0.5 \mathrm{eV}$ per molecule $\left(\mathrm{H}_{2} \mathrm{O} / \mathrm{PH}_{3}\right)$ for the $100 \mathrm{nA}$ irradiation, and these values scale linearly to 1000 and $5000 \mathrm{nA}$. The density of the ice mixture used for the CASINO simulation was the weighted average to the ice components: $0.90 \mathrm{~g} \mathrm{~cm}^{-3}$ for $\mathrm{PH}_{3}^{46,50}, 0.94 \mathrm{~g} \mathrm{~cm}^{-3}$ for $\mathrm{H}_{2} \mathrm{O}^{51}$, and $1.11 \mathrm{~g} \mathrm{~cm}^{-3}$ for $\mathrm{CO}_{2}{ }^{47}$. A Nicolet 6700 Fourier Transform Infrared Spectrometer monitored the ice during irradiation from 500 to $4000 \mathrm{~cm}^{-1}$ with 4 $\mathrm{cm}^{-1}$ resolution. Standard experiments utilized oxygen-18-labeled $\mathrm{CO}_{2}$ and $\mathrm{H}_{2} \mathrm{O}$ and were repeated at $5000 \mathrm{nA}$ irradiation with non-isotopically labeled $\mathrm{CO}_{2}$ and $\mathrm{H}_{2} \mathrm{O}$ in order to confirm the infrared assignments, and both isotopologues are presented in Supplementary Tables 1 and 2.

PI-ReTOF-MS. After the irradiation, the ices were annealed at $1 \mathrm{~K} \mathrm{~min}^{-1}$ while any subliming molecules were detected using a reflectron time-of-flight (ReTOF) mass spectrometer (Jordon TOF Products, Inc.) with single-photon ionization (PI) ${ }^{45}$. This photoionization process utilizes difference four wave mixing to produce vacuum ultraviolet light $\left(\omega_{\mathrm{vuv}}=2 \omega_{1}-\omega_{2}\right)$. These experiments were performed with $10.86 \mathrm{eV}$ photoionization energy and repeated at $9.93 \mathrm{eV}$ to distinguish between the isomers of the phosphorus oxoacids. To produce $10.86 \mathrm{eV}$, the second harmonic $(532 \mathrm{~nm})$ of a pulsed neodymium-doped yttrium aluminum garnet laser (Nd:YAG, Spectra Physics, PRO-270, $30 \mathrm{~Hz})$ was used to pump a Rhodamine $610 / 640$ dye mixture $(0.17 / 0.04 \mathrm{~g} \mathrm{~L}$ -1 ethanol) to obtain $607 \mathrm{~nm}$, which underwent a tripling process to achieve $\omega_{1}=$ $202 \mathrm{~nm}$. A second Nd:YAG laser pumped an LDS $867\left(0.15 \mathrm{~g} \mathrm{~L}^{-1}\right.$ ethanol) dye to obtain $\omega_{2}=890 \mathrm{~nm}$, which when combined with $2 \omega_{1}$, using krypton as a non-linear medium, generated $\omega_{\text {vuv }}=114 \mathrm{~nm}(10.86 \mathrm{eV})$ at $10^{14}$ photons per pulse. The production of $9.93 \mathrm{eV}$ occurred similarly except the second harmonic $(532 \mathrm{~nm})$ of the second Nd:YAG laser was used as $\omega_{2}$. The VUV light was spatially separated from other wavelengths using a lithium fluoride (LiF) biconvex lens (ISP Optics) and directed $1 \mathrm{~mm}$ above the sample to ionize subliming molecules. The ionized molecules 
were mass analyzed with the ReTOF mass spectrometer where the arrival time to a multichannel plate is based on mass-to-charge ratios, and the signal was amplified with a fast preamplifier (Ortec 9305) and recorded with a bin width of $4 \mathrm{~ns}$ triggered at $30 \mathrm{~Hz}$ (Quantum Composers, 9518). The ReTOF recorded until the sample reached $300 \mathrm{~K}$ and held at constant temperature for $1 \mathrm{~h}$, after which an infrared spectrum of the resulting residue was recorded.

SIMS. After each experiment, the wafer was removed and stored in an air-tight container under inert nitrogen atmosphere. The residue on the wafer was analyzed utilizing a time-of-flight secondary ion mass spectrometry instrument (TOF-SIMS 5-300, ION-TOF) equipped with a reflectron mass analyzer, a $30 \mathrm{keV} \mathrm{Bi}{ }_{n}$ liquid metal primary ion source (Bi-LMIG), and a low-energy electron flood gun. Spectra were acquired with $\mathrm{Bi}_{3}{ }^{+}$in bunched mode with a focus of $2-3 \mathrm{~mm}$, a beam current of $0.25 \mathrm{pA}$, and a total dose of $1.25 \times 10^{8}$ ions. Data were acquired from a $500 \mu \mathrm{m}^{2}$ analysis area. The positive and negative ions from the sputtered residue were recorded, and the residues were analyzed and compared with fragment assignments from calibrated phosphorus oxoacids adjusted for the mass shifts since our studies utilized ${ }^{18} \mathrm{O}$-labeled precursors.

GCXGC-TOF-MS. The gas chromatographic analysis was carried out by a GC $\times \mathrm{GC}$ Pegasus IV D instrument coupled to a time-of-flight mass spectrometer ((TOFMS), LECO Corp.). The TOF-MS system operated at a storage rate of $150 \mathrm{~Hz}$, with a $25-700 \mathrm{amu}$ mass range, a detector voltage of $1.5-1.8 \mathrm{kV}$, and a solvent delay of $12 \mathrm{~min}$. The ion source and transfer temperatures were set to $503 \mathrm{~K}$. The column set consisted of an Agilent J\&W DB 5MS Ultra Inert primary column $(30 \mathrm{~m} \times 0.25$ $\mathrm{mm}$ inner diameter (ID), $0.25 \mu \mathrm{m}$ film thickness) Press-Tight (Restek Corp.) connected to an Agilent DB Wax secondary column $(1.40 \mathrm{~m} \times 0.1 \mathrm{~mm}$ ID, $0.1 \mu \mathrm{m}$ film thickness). Helium was used as carrier gas at a constant flow rate $\bar{u}=1 \mathrm{~mL}$ $\mathrm{min}^{-1}$. Sample volumes of $1 \mu \mathrm{L}$ were injected in the splitless mode into an ultra inert, single taper w/glass wool splitless inlet liner (Agilent) at an injector temperature of $503 \mathrm{~K}$. All samples and reference compounds were analyzed with the identical temperature program. The primary oven was operated as follows: $313 \mathrm{~K}$ for $1 \mathrm{~min}$, temperature increase of $5 \mathrm{~K} \mathrm{~min}^{-1}$ to $473 \mathrm{~K}$ and held for $15 \mathrm{~min}$. The secondary oven used the same temperature program with a constant temperature offset of $303 \mathrm{~K}$. A modulation period of $5 \mathrm{~s}$ was applied for the liquid nitrogen cooled thermal modulator. Data were acquired and processed with LECO Corp. ChromaTOF software. Compound identification was performed by comparison with the chromatographic retention in both dimensions and mass spectra of authentic standards. The derivatization reagents including $\mathrm{N}, \mathrm{O}$-bis(trimethylsilyl) trifluoroacetamide (BSTFA) and trimethylsilyl chloride (TMCS), the internal standard methyl laurate, hexane, and water as well as phosphonic acid (HPO $\left.(\mathrm{OH})_{2}\right)$, phosphoric acid $\left(\mathrm{H}_{3} \mathrm{PO}_{4}\right)$, pyrophosphoric acid $\left(\mathrm{H}_{4} \mathrm{P}_{2} \mathrm{O}_{7}\right)$, and sodium triphosphate $\left(\mathrm{Na}_{5} \mathrm{P}_{3} \mathrm{O}_{10}\right)$ were purchased from Sigma-Aldrich. Sample handling glassware was wrapped in aluminum foil and heated at $773 \mathrm{~K}$ for $3 \mathrm{~h}$ prior to usage to eliminate possible contamination. Eppendorf tips were sterile and the water used for extraction, standard solutions, reagent solutions, and blanks were of highperformance liquid chromatography grade. The residues were extracted with $10 \times$ $50 \mu \mathrm{L}$ water from their silver wafers and transferred into conical reaction vials $(1$ $\mathrm{mL}$ V-Vial, Wheaton). The aqueous extracts were dried under a gentle stream of nitrogen and silylated with an excess of $50 \mu \mathrm{L}$ BSTFA and $10 \mu \mathrm{L}$ TMCS for $2 \mathrm{~h}$ at $353 \mathrm{~K}$ in the presence of the internal standard methyl laurate in hexane $\left(5 \mu \mathrm{L}, 10^{-5}\right.$ $\mathrm{M})$. The derivatized mixtures were transferred into GC vials for their subsequent GC $\times$ GC-TOF-MS analysis. Procedural blanks were run in sequence to each sample in order to monitor background interferences.

Compound identification was performed by comparison with the chromatographic retention in both dimensions of authentic standards and mass spectra. Comparison with previously reported data on TMS derivatives of phosphorus oxoacids $s^{31,43,44}$ let us identify multiple oxoacids. Supplementary Table 6 summarizes the analytes' retention times in the first and second chromatographic dimension as well as the corresponding mass spectra of the analyzed residue and standard. The mass spectra of all three phosphorus oxoacids are characterized by the molecular ion $[\mathrm{M}]^{+}$peak, the fragment ion $[\mathrm{M}-15]^{+}$ formed by the loss of a methyl group as well as silicon-containing fragments at $\mathrm{m} / \mathrm{z}$ $45\left[\mathrm{CH}_{3} \mathrm{SiH}_{2}\right], 73\left[\left(\mathrm{CH}_{3}\right)_{3} \mathrm{Si}\right], 75\left[\left(\mathrm{CH}_{3}\right)_{3} \mathrm{SiH}_{2}\right], 133\left[\left(\mathrm{CH}_{3}\right)_{3} \mathrm{Si}_{2} \mathrm{O}_{2}\right], 147$ $\left[\left(\mathrm{CH}_{3}\right)_{5} \mathrm{Si}_{2} \mathrm{O}\right]$, and $207\left[\left(\mathrm{CH}_{3}\right)_{5} \mathrm{Si}_{3} \mathrm{O}_{3}\right]$. The phosphorus oxoacids detected in the residues were found to contain ${ }^{18} \mathrm{O}$ isotopes, whereas the standard samples used for identification were made of the natural isotopic composition dominated by ${ }^{16} \mathrm{O}$. Esterfication, necessary to increase the volatility of our target compounds in the gas chromatographic analysis, resulted in a shift of the tautomeric equilibria of phosphonic and phosphinic acid toward their more active pyramidal forms (Supplementary Fig. 1).

Theoretical. For the theoretical calculations, the geometries of neutral molecules and cations were optimized by the hybrid density functional B3LYP ${ }^{52-55}$ with the cc-pVTZ basis set and thus obtained the harmonic frequencies. Their coupled cluster ${ }^{56-59} \operatorname{CCSD}(\mathrm{T}) / \mathrm{cc}-\mathrm{pVDZ}, \mathrm{CCSD}(\mathrm{T}) / \mathrm{cc}-\mathrm{pVTZ}$, and $\mathrm{CCSD}(\mathrm{T}) / \mathrm{cc}-\mathrm{pVQZ}$ energies were then calculated and extrapolated to completed basis set limits ${ }^{60}$, $\operatorname{CCSD}(\mathrm{T}) / \mathrm{CBS}$, with B3LYP/cc-pVTZ zero-point energy corrections. The energies are accurate within $0.08 \mathrm{eV}^{61}$. The adiabatic ionization energies were computed by taking the energy difference between the ionic and the neutral states that correspond to similar conformation. At this level of theory, the adiabatic ionization energies are within $0.05 \mathrm{eV}$. The GAUSSIAN09 program $^{62}$ was utilized in the electronic structure calculations.

\section{Data availability}

The data that support the findings of the current research are available from the corresponding author on request.

Received: 21 April 2018 Accepted: 29 August 2018

Published online: 21 September 2018

\section{References}

1. Gulick, A. Phosphorus as a factor in the origin of life. Am. Sci. 43, 479-489 (1955).

2. Pasek, M. A., Gull, M. \& Herschy, B. Phosphorylation on the early earth. Chem. Geol. 475, 149-170 (2017).

3. Keefe, A. D. \& Miller, S. L. Are polyphosphates or phosphate esters prebiotic reagents? J. Mol. Evol. 41, 693-702 (1995).

4. Cooper, G. W., Onwo, W. M. \& Cronin, J. R. Alkyl phosphonic acids and sulfonic acids in the Murchison meteorite. Geochim. Cosmochim. Acta 56, 4109-4115 (1992).

5. Bennett, C. J., Jamieson, C., Mebel, A. M. \& Kaiser, R. I. Untangling the formation of the cyclic carbon trioxide isomer in low temperature carbon dioxide ices. Phys. Chem. Chem. Phys. 6, 735-746 (2004).

6. Agundez, M., Cernicharo, J., Decin, L., Encrenaz, P. \& Teyssier, D. Confirmation of circumstellar phosphine. Astrophys. J. Lett. 790, L27 (2014).

7. Guélin, M., Cernicharo, J., Paubert, G. \& Turner, B. Free CP in IRC+10216. Astron. Astrophys. 230, L9-L11 (1990).

8. Halfen, D., Clouthier, D. \& Ziurys, L. M. Detection of the CCP Radical $\left(X^{2} \Pi_{r}\right)$ in IRC + 10216: a new interstellar phosphorus-containing species. Astrophys. J. Lett. 677, L101 (2008)

9. Agúndez, M., Cernicharo, J. \& Guélin, M. Discovery of phosphaethyne (HCP) in space: phosphorus chemistry in circumstellar envelopes. Astrophys. J. Lett. 662, L91 (2007).

10. Turner, B. \& Bally, J. Detection of interstellar PN-The first identified phosphorus compound in the interstellar medium. Astrophys. J. 321, L75-L79 (1987).

11. Ziurys, L. Detection of interstellar PN-the first phosphorus-bearing species observed in molecular clouds. Astrophys. J. 321, L81-L85 (1987)

12. Milam, S. et al. Constraining phosphorus chemistry in carbon-and oxygenrich circumstellar envelopes: observations of PN, HCP, and CP. Astrophys. J. 684, 618 (2008).

13. Agundez, M., Cernicharo, J. \& Guelin, M. New molecules in IRC +10216 confirmation of C5S and tentative identification of $\mathrm{MgCCH}, \mathrm{NCCP}$, and $\mathrm{SiH}_{3} \mathrm{CN}$. Astron. Astrophys. 570, A45 (2014).

14. Ridgway, S., Wallace, L. \& Smith, G. The 800-1200 inverse centimeter absorption spectrum of Jupiter. Astrophys. J. 207, 1002-1006 (1976).

15. Larson, H., Fink, U., Smith, H. \& Davis, D. The middle-infrared spectrum of Saturn-Evidence for phosphine and upper limits to other trace atmospheric constituents. Astrophys. J. 240, 327-337 (1980).

16. Altwegg, K. et al. Prebiotic chemicals-amino acid and phosphorus-in the coma of comet 67P/Churyumov-Gerasimenko. Sci. Adv. 2, el600285 (2016).

17. Fuchs, L. H. Meteorite Research 683-695 (Springer, Dordrecht, 1969).

18. de Graaf, R. M., Visscher, J. \& Schwartz, A. W. A plausibly prebiotic synthesis of phosphonic-acids. Nature 378, 474-477 (1995)

19. Pasek, M. A. \& Lauretta, D. S. Aqueous corrosion of phosphide minerals from iron meteorites: a highly reactive source of prebiotic phosphorus on the surface of the early earth. Astrobiology 5, 515-535 (2005).

20. Pasek, M. A. Rethinking early earth phosphorus geochemistry. PNAS 105 , 853-858 (2008)

21. Pasek, M. A., Harnmeijer, J. P., Buick, R., Gull, M. \& Atlas, Z. Evidence for reactive reduced phosphorus species in the early Archean ocean. PNAS 110, 10089 (2013)

22. La Cruz, N. L. et al. The evolution of the surface of the mineral schreibersite in prebiotic chemistry. Phys. Chem. Chem. Phys. 18, 20160-20167 (2016).

23. Gull, M. et al. Nucleoside phosphorylation by the mineral schreibersite. Sci. Rep. 5, 17198 (2015).

24. Boogert, A. A., Gerakines, P. A. \& Whittet, D. C. Observations of the icy universe. Annu. Rev. Astron. Astrophys. 53, 541-581 (2015).

25. Turner, A. M., Abplanalp, M. J., Blair, T. J., Dayuha, R. \& Kaiser, R. I. An infrared spectroscopic study toward the formation of alkylphosphonic acids and their precursors in extraterrestrial environments. Astrophys. J. Suppl. Ser. 234, 6 (2018). 
26. Withnall, R. \& Andrews, L. Infrared spectra of oxygen atom-phosphine reaction products trapped in solid argon. J. Phys. Chem. 92, 4610-4619 (1988).

27. Withnall, R. \& Andrews, L. FTIR spectra of the photolysis products of the phosphine-ozone complex in solid argon. J. Phys. Chem. 91, 784-797 (1987).

28. Kostko, O., Bandyopadhyay, B. \& Ahmed, M. Vacuum ultraviolet photoionization of complex chemical systems. Annu. Rev. Phys. Chem. 67, 19-40 (2016)

29. Zinbo, M. \& Sherman, W. R. Mass spectrometry of tris (trimethylsilyl) phosphate. Tetrahedron Lett. 10, 2811-2813 (1969).

30. Butts, W. C. \& Rainey, W. T. Gas chromatography and mass spectrometry of the trimethylsilyl derivatives of inorganic anions. Anal. Chem. 43, 538-542 (1971).

31. Little, J. L. Artifacts in trimethylsilyl derivatization reactions and ways to avoid them. J. Chromatogr. A 844, 1-22 (1999).

32. Harvey, D. \& Horning, M. Characterization of the trimethylsilyl derivatives of sugar phosphates and related compounds by gas chromatography and gas chromatography-mass spectrometry. J. Chromatogr. A 76, 51-62 (1973).

33. Zheng, W., Kim, Y. S. \& Kaiser, R. I. Formation of nitric oxide and nitrous oxide in electron-irradiated $\mathrm{H}_{2}{ }^{18} \mathrm{O} / \mathrm{N}_{2}$ ice mixtures-evidence for the existence of free oxygen atoms in interstellar and solar system analog ices. Phys. Chem. Chem. Phys. 13, 15749-15754 (2011).

34. Zheng, W., Jewitt, D. \& Kaiser, R. I. Formation of hydrogen, oxygen, and hydrogen peroxide in electron-irradiated crystalline water ice. Astrophys. J. 639, 534 (2006).

35. Zheng, W., Jewitt, D. \& Kaiser, R. I. Temperature dependence of the formation of hydrogen, oxygen, and hydrogen peroxide in electron-irradiated crystalline water ice. Astrophys. J. 648, 753 (2006).

36. Turner, A. M., Abplanalp, M. J. \& Kaiser, R. I. Probing the carbon-phosphorus bond coupling in low-temperature phosphine $\left(\mathrm{PH}_{3}\right)$-methane $\left(\mathrm{CH}_{4}\right)$ interstellar ice analogues. Astrophys. J. 819, 97 (2016).

37. Hamilton, P. A. \& Murrells, T. P. Mechanism for the chemiluminescence in oxygen-phosphorus system. J. Phys. Chem. 90, 182-185 (1986).

38. Schmidt, M. W., Yabushita, S. \& Gordon, M. S. Structure, bonding, and internal rotation in phosphine oxide $\left(\mathrm{H}_{3} \mathrm{PO}\right)$, hydroxyphosphine $\left(\mathrm{H}_{2} \mathrm{POH}\right)$, and hydroxyfluorophosphine (HFPOH). J. Phys. Chem. 88, 382-389 (1984)

39. Nava, D. F. \& Stief, L. J. Temperature study of oxygen atom + phosphine reaction rate: kinetic measurements and planetary atmospheric implications. J. Phys. Chem. 93, 4044-4047 (1989).

40. Stief, L., Payne, W. \& Nava, D. Rate constant for the reaction of atomic oxygen with phosphine at 298 K. J. Chem. Phys. 87, 2112-2115 (1987).

41. Balucani, N. Elementary reactions and their role in gas-phase prebiotic chemistry. Int. J. Mol. Sci. 10, 2304-2335 (2009).

42. Gorrell, I. B. et al. On the origin of the Murchison meteorite phosphonates Implications for pre-biotic chemistry. Chem. Commun. 21, 1643-1645 (2006).

43. Nam, I., Lee, J. K., Nam, H. G. \& Zare, R. N. Abiotic production of sugar phosphates and uridine ribonucleoside in aqueous microdroplets. PNAS 2017, 14896 (2017).

44. Gibard, C., Bhowmik, S., Karki, M., Kim, E.-K. \& Krishnamurthy, R Phosphorylation, oligomerization and self-assembly in water under potential prebiotic conditions. Nat. Chem. 10, 212-217 (2018).

45. Jones, B. M. \& Kaiser, R. I. Application of reflectron time-of-flight mass spectroscopy in the analysis of astrophysically relevant ices exposed to ionization radiation: methane $\left(\mathrm{CH}_{4}\right)$ and $\mathrm{D} 4$-methane $\left(\mathrm{CD}_{4}\right)$ as a case study. J. Phys. Chem. Lett. 4, 1965-1971 (2013).

46. Turner, A. M. et al. A photoionization mass spectroscopic study on the formation of phosphanes in low temperature phosphine ices. Phys. Chem. Chem. Phys. 17, 27227-27902 (2015)

47. Bouilloud, M. et al. Bibliographic review and new measurements of the infrared band strengths of pure molecules at $25 \mathrm{~K}: \mathrm{H}_{2} \mathrm{O}, \mathrm{CO}_{2}, \mathrm{CO}, \mathrm{CH}_{4}, \mathrm{NH}_{3}$, $\mathrm{CH}_{3} \mathrm{OH}, \mathrm{HCOOH}$ and $\mathrm{H}_{2}$ CO. Mon. Not. R. Astron. Soc. 451, 2145-2160 (2015).

48. Westley, M., Baratta, G. \& Baragiola, R. Density and index of refraction of water ice films vapor deposited at low temperatures. J. Chem. Phys. 108, 3321-3326 (1998).

49. Hovington, P., Drouin, D. \& Gauvin, R. CASINO: a new Monte Carlo code in $\mathrm{C}$ language for electron beam interaction-part I: description of the program. Scanning 19, 1-14 (1997).

50. Francia, M. D. \& Nixon, E. R. Infrared study of solid phosphine. J. Chem. Phys. 58, 1061-1065 (1973).

51. Hagen, W., Tielens, A. \& Greenberg, J. The infrared spectra of amorphous solid water and ice Ic between 10 and 140 K. Chem. Phys. 56, 367-379 (1981).

52. Becke, A. D. Density-functional thermochemistry. I. The effect of the exchange-only gradient correction. J. Chem. Phys. 96, 2155-2160 (1992).
53. Becke, A. D. Density-functional thermochemistry. II. The effect of the Perdew-Wang generalized-gradient correlation correction. J. Chem. Phys. 97, 9173-9177 (1992)

54. Becke, A. D. Density-functional thermochemistry. III. The role of exact exchange. J. Chem. Phys. 98, 5648-5652 (1993).

55. Lee, C., Yang, W. \& Parr, R. G. Development of the Colle-Salvetti correlationenergy formula into a functional of the electron density. Phys. Rev. B 37, 785 (1988).

56. Purvis, G. D. III \& Bartlett, R. J. A full coupled-cluster singles and doubles model: the inclusion of disconnected triples. J. Chem. Phys. 76, 1910-1918 (1982).

57. Hampel, C., Peterson, K. A. \& Werner, H.-J. A comparison of the efficiency and accuracy of the quadratic configuration interaction (QCISD), coupled cluster (CCSD), and Brueckner coupled cluster (BCCD) methods. Chem. Phys. Lett. 190, 1-12 (1992)

58. Knowles, P. J., Hampel, C. \& Werner, H. J. Coupled cluster theory for high spin, open shell reference wave functions. J. Chem. Phys. 99, 5219-5227 (1993).

59. Deegan, M. J. \& Knowles, P. J. Perturbative corrections to account for triple excitations in closed and open shell coupled cluster theories. Chem. Phys. Lett. 227, 321-326 (1994).

60. Peterson, K. A., Woon, D. E. \& Dunning, T. H. Jr Benchmark calculations with correlated molecular wave functions. IV. The classical barrier height of the $\mathrm{H}+\mathrm{H}_{2} \rightarrow \mathrm{H}_{2}+\mathrm{H}$ reaction. J. Chem. Phys. 100, 7410-7415 (1994).

61. Peterson, K. A. \& Dunning, T. H. Jr Intrinsic errors in several ab initio methods: the dissociation energy of $\mathrm{N}_{2}$. J. Phys. Chem. 99, 3898-3901 (1995).

62. Frisch, M. J. GAUSSIAN 09, Revision D.01 (Gaussian, Inc., Wallingford, CT, 2013).

\section{Acknowledgements}

This work was supported by NASA under Grant NNX16AD27G to The University of Hawaii. The Hawaii group would also like to thank the W.M. Keck Foundation to fund the surface science machine. This work has also been supported by the French government through the UCA ${ }^{\mathrm{JEDI}}$ Investments in the Future project managed by the National Research Agency (ANR) with the reference number ANR-15-IDEX-01. A.H.H C., B.-J.S., and K.-H.C. thank the National Center for High-performance Computer in Taiwan for providing the computer resources utilized in the calculations.

\section{Author contributions}

A.M.T., A.B., M.J.A., C.Z., and S.G. carried out the experiments; C.M. performed the gas chromatography analysis; B.-J.S., K.-H.C., and A.H.H.C. carried out the theoretical calculations; AM.T. analyzed the experimental data; A.M.T. and R.I.K. wrote the manuscript; and R.I.K. supervised the study.

\section{Additional information}

Supplementary Information accompanies this paper at https://doi.org/10.1038/s41467 018-06415-7.

Competing interests: The authors declare no competing interests.

Reprints and permission information is available online at http://npg.nature.com/ reprintsandpermissions/

Publisher's note: Springer Nature remains neutral with regard to jurisdictional claims in published maps and institutional affiliations.

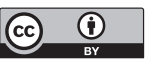

Open Access This article is licensed under a Creative Commons Attribution 4.0 International License, which permits use, sharing, adaptation, distribution and reproduction in any medium or format, as long as you give appropriate credit to the original author(s) and the source, provide a link to the Creative Commons license, and indicate if changes were made. The images or other third party material in this article are included in the article's Creative Commons license, unles indicated otherwise in a credit line to the material. If material is not included in the article's Creative Commons license and your intended use is not permitted by statutory regulation or exceeds the permitted use, you will need to obtain permission directly from the copyright holder. To view a copy of this license, visit http://creativecommons.org/ licenses/by/4.0/

(c) The Author(s) 2018 